\title{
Efeitos da embalagem em atmosfera modificada sobre as alterações microbiológicas, químicas e sensoriais de pargo (Pagrus pagrus)
}

\section{Effects of modified atmosphere packaging on microbiological, chemical and sensory changes of pargo (Pagrus pagrus)}

\author{
Raquel Lima Salgado, ${ }^{*}$ Juliana de Castro Beltrão da Costa, ${ }^{* *}$ Carlos Adam Conte Júnior, ${ }^{* * *}$ Manuela Fernández, ${ }^{* * *}$ \\ Mônica Queiroz de Freitas, ${ }^{* \star * *}$ Sérgio Borges Mano*****
}

\begin{abstract}
Resumo
Para avaliar os efeitos da embalagem em atmosfera modificada na vida útil do pargo (Pagrus pagrus), 20 amostras foram submetidas a quatro diferentes tratamentos: $100 \%$ ar, $100 \% \mathrm{CO}_{2}, 100 \% \mathrm{~N}_{2}$, e $50 / 50 \mathrm{CO}_{2} / \mathrm{N}_{2}$. Durante os 16 dias de estocagem foram coletadas amostras para contagem total de bactérias heterotróficas aeróbias mesófilas (CTBHAM), pH e avaliação sensorial de cor e odor. Os resultados obtidos foram organizados em tabelas e gráficos para realização de uma análise estatística descritiva. $\mathrm{O}$ crescimento bacteriano foi mais acelerado, respectivamente, nas amostras embaladas em $100 \%$ ar, $100 \% \mathrm{~N}_{2}$ e $50 / 50 \mathrm{CO}_{2} / \mathrm{N}_{2}$, sendo os menores crescimentos observados nas embaladas em $100 \% \mathrm{CO}_{2}$. As amostras em aerobiose apresentaram um aumento do $\mathrm{pH}$, atingindo um máximo de 7,07 no 8 dia de estocagem, assim como as amostras embaladas em $100 \% \mathrm{~N}_{2}$ atingiram um valor máximo de 7,49 no 16 dia. Os aspectos sensoriais da degradação foram primeiramente observados no ar e mais tardiamente em $100 \% \mathrm{CO}_{2}$. Pode-se concluir que a embalagem contendo $100 \% \mathrm{CO}_{2}$ se destacou das demais, mostrando bom desempenho na preservação da carne de pargo, aumentando sua vida útil e sendo a mais eficiente na manutenção dos parâmetros de qualidade.
\end{abstract}

Palavras-chave: peixe, pargo (Pagrus pagrus), atmosfera modificada, vida útil.

\begin{abstract}
For evaluate the effects of modified-atmosphere packaging on the shelf-life of pargo (Pagrus pagrus), 20 samples were submitted to 4 treatments: $100 \%$ air, $100 \% \mathrm{CO}_{2}, 100 \% \mathrm{~N}_{2}$, and $50 / 50 \mathrm{CO}_{2} / \mathrm{N}_{2}$. During the 16 days of storage, samples were collected to determine total viable count (TVC), $\mathrm{pH}$ and sensory evaluation of color and odor. The results obtained were arranged in tables and grafics so as to make the analysis descriptive statistics. In the results was found a most quickly bacteria grew in pargo stored in $100 \%$ air, followed by those in $100 \% \mathrm{~N}_{2}$ and $50 / 50 \% \mathrm{CO}_{2} / \mathrm{N}_{2}$ respectively, and the lowest counts were with $100 \%$ $\mathrm{CO}_{2}$. The samples packed under aerobiosis showed an increase in their $\mathrm{pH}$, reaching a maximum of 7,07 on the $8^{\text {th }}$ day, as well the samples packed in $100 \% \mathrm{~N}_{2}$ which had a maximum of 7,49 on the $16^{\text {th }}$ day. Sensory aspects of degradation were earlier found in air and latter in $100 \% \mathrm{CO}_{2}$. According to the results, it can be concluded that the $100 \% \mathrm{CO}_{2}$ packing stood out in relation to the others, showing good performance preserving pargo meat, extending shelf-life, being effective in keeping the quality parameters.
\end{abstract}

Keywords: fish, pargo (Pagrus pagrus), modified atmosphere, shelf-life.

\section{Introdução}

No Brasil o pescado situa-se entre as quatro maiores fontes de proteína animal para o consumo humano. As últimas estimativas indicam que a produção pesqueira tem evoluído significativamente nos últimos anos, sendo o total produzido, incluindo a pesca extrativa costeira, continental, oceânica e a aqüicultura de 728 mil toneladas em 1994, passando a 985 mil toneladas em 2002 (IBAMA, 2005).

Estes fatos demonstram que a pesca brasileira é um componente fundamental para a socioeconomia do país,

\footnotetext{
* Programa de Pós-graduação em Medicina Veterinária (Doutorado) - Higiene Veterinária e Processamento Tecnológico de Produtos de Origem Animal da Faculdade de Veterinária da Universidade Federal Fluminense. Rua Vital Brazil Filho, 64. CEP 24230-340 - Niterói, RJ - Brasil.

** Discente de Medicina Veterinária (Bolsista PIBIC). Faculdade de Veterinária - Universidade Federal Fluminense.

*** Programa de Pós-graduação em Ciencias Veterinárias - Departamento de Nutrición, Bromatología y Tecnología de los Alimentos - Universidad Complutense de Madrid - Espana.

${ }^{* * * *}$ Departamento de Nutrición, Bromatología y Tecnología de los Alimentos - Universidad Complutense de Madrid - España.

${ }^{* * * * *}$ Departamento de Tecnologia dos Alimentos da Faculdade de Veterinária da Universidade Federal Fluminense.

Autores prara correspondência: Sérgio Borges Mano. E-mail: mtasbm@vm.uff.br. Raquel Lima Salgado. E-mail: rlsalgado@vm.uff.br
} 
sendo o pargo (Pagrus pagrus) uma das espécies de maior interesse comercial devido à qualidade de sua carne.

Por ser um alimento altamente perecível, o pescado exige cuidados especiais na sua manipulação, estando sujeito à contaminação pelos mais variados microrganismos, adquiridos no próprio ambiente aquático, ou durante as diferentes etapas de captura, transporte e distribuição. Estes microrganismos podem influenciar no prazo de vida comercial do pescado em aerobiose, já reduzido em função da sua própria composição biológica e limitado pelo processo de deterioração enzimática e microbiológica, acarretando um tempo restrito de comercialização e distribuição, principalmente quando transportado a longas distâncias.

As modificações de $\mathrm{pH}$ ocasionadas pela decomposição do pescado têm origem na atividade enzimática e ação das bactérias que modificam a concentração de íons livres disponíveis (Ogawa e Maia, 1999). A queda do pH após a captura está diretamente relacionada com as condições de pesca, onde quanto maior for a resistência do peixe à captura e maior for o seu nível de estresse e fadiga, menores serão as reservas de glicogênio muscular, ocasionando uma menor produção de ácido lático, diminuindo o $\mathrm{pH}$ final do pescado.

De maneira geral, quando mantido sob refrigeração e gelo, a vida útil do pescado pode variar de dois a 14 dias, dependendo da espécie, local de captura e estação do ano (Stammen et al., 1990). Em função do reduzido prazo de vida comercial, da crescente demanda por produtos frescos e, ainda, da necessidade de redução de custos relacionados com a energia utilizada nos processos de refrigeração e congelamento, justifica-se a busca por tecnologias que permitam um aumento no prazo de vida comercial de alimentos altamente perecíveis e com alto teor protéico como peixes, carnes vermelhas e aves (Mano et al., 1999; Lopes et al., 2004; Conte-Junior et al., 2006). Atendendo a esta demanda, tem-se investido em estudos de embalagens em atmosfera modificada (EAM).

O método de EAM consiste em substituir a atmosfera que rodeia o produto por um gás ou mistura de gases, especialmente desenvolvidos para cada tipo de alimento. A tecnologia de EAM é atualmente difundida em praticamente todos os países desenvolvidos, e cerca de $10 \%$ a $40 \%$ dos produtos de origem animal já são comercializados sob EAM. A Noruega é o país onde se verifica a maior proporção de alimentos comercializados sob EAM, com aproximadamente $60 \%$ do total dos alimentos comercializados no país (Sorheim e Nissen, 2005).

A eficiência do $\mathrm{CO}_{2}$ na conservação do pescado foi constatada por diversos autores, como Dalgaard et al. (1993) e Devebere e Boskou (1996) em filés de bacalhau (Gadus morhua); LópezGálvez et al. (1995) em filés de atum (Thunnus alalunga); Ordóñez et al. (2000) em merluza (Merluccius merluccius); Lopes et al. (2004) e Özogul et al. (2004) em sardinhas (Sardinella brasiliensis e Sardina pilchardus, respectivamente); Souza (2004) em lombo de atum (Thunnus albacares); Albanese et al. (2005) em sépias (Sepia officinalis); Lalitha et al. (2005) em crómida verde (Etroplus suratensis Bloch); e Poli et al. (2006) em robalo (Dicentrarchus labrax). Todos esses autores observaram um aumento de vida útil destes produtos quando submetidos à ação do $\mathrm{CO}_{2}$ em variadas concentrações.
Tendo em vista o exposto acima, objetivou-se identificar as concentrações e misturas de gases que apresentassem melhor desempenho e, portanto, maior aplicabilidade na conservação desta espécie de pescado sob refrigeração, interferindo no aumento do seu prazo de vida comercial.

\section{Material e métodos}

Os exemplares de pargo (Pagrus pagrus) foram obtidos no entreposto de pesca - Mercado de São Pedro, localizado em Niterói/RJ. Os peixes foram acondicionados em caixas de poliestireno com gelo, e transportados até o Laboratório de Microbiologia de Alimentos, da Faculdade de Veterinária da Universidade Federal Fluminense, onde as amostras foram colhidas e processadas.

Uma vez no laboratório os peixes foram lavados com água destilada esterilizada com o objetivo de homogeneizar a possível contaminação inicial, e tiveram os seus lombos seccionados em 20 fragmentos de 25 gramas cada, que foram acondicionados em embalagens plásticas "Cryovac BBL4" com estrutura multicamadas de baixa permeabilidade a gases, contendo um litro de gás ou mistura de gases predeterminada de: $100 \%$ ar atmosférico; 50/50 $\mathrm{CO}_{2} / \mathrm{N}_{2}$; $100 \% \mathrm{~N}_{2}$; e $100 \% \mathrm{CO}_{2}$. As embalagens foram termo-seladas e acondicionadas à temperatura de refrigeração $\left(2,0 \pm 2,0^{\circ} \mathrm{C}\right)$.

A tomada de amostras para microbiologia ocorreu nos dias 1, 4, 8,12 e 16 de estocagem. Foram realizadas diluições consecutivas com solução salina peptonada $0,1 \%$ estéril que serviram tanto para as análises bacteriológicas quanto para aferição do $\mathrm{pH}$.

Para contagem de bactérias heterotróficas aeróbias e mesófilas (CTBHAM) empregou-se a metodologia descrita pelo LANARA (Brasil, 1981a). As amostras de tecido muscular ( $25 \mathrm{~g}$ ) foram homogeneizadas com $225 \mathrm{~mL}$ de solução salina peptonada em aparelho de "Stomacher" durante 1 minuto. Foram realizadas diluições consecutivas e $0,1 \mathrm{~mL}$ de cada diluição foi transferido a uma placa de Petri contendo meio Ágar Padrão para Contagem (APC). Utilizou-se o meio de cultura Ágar Padrão para Contagem (APC) marca Oxoid, na forma de Pour-Plate, com incubação a $35^{\circ} \mathrm{C}$ por $24 / 48 \mathrm{~h}$.

A aferição do $\mathrm{pH}$ foi feita a partir da diluição da amostra em solução salina peptonada $0,1 \%$, utilizando o método potenciométrico, que se baseia na determinação instrumental do $\mathrm{pH}$ (Brasil, 1981b), e seguiu o mesmo padrão de dias das análises microbiológicas.

A análise sensorial foi realizada no momento da abertura da embalagem e se baseou nos parâmetros cor, odor e aspecto através de uma análise descritiva.

Os resultados foram tratados estatisticamente através de uma análise descritiva simples, onde foi realizado um estudo comparativo com utilização de tabelas e figuras.

\section{Resultados e discussão}

Os resultados referentes à contagem total de bactérias heterotróficas aeróbias mesófilas estão representados, na forma de curva de crescimento bacteriano, na Figura 1. Observou-se um acelerado e intenso crescimento bacteriano nas amostras embaladas em aerobiose, onde estas apresentaram valores acima de Log 6,0 unidades formadoras 
de colônias (UFC)/g ainda no 4 $^{\circ}$ dia de estocagem, e acima de $\log 7$ UFC/g no $8^{\circ}$ dia de estocagem. Tal crescimento é reflexo da inadequação do ar como forma de preservação de alimentos, conforme constatado por Poli et al. (2006) que, ao estudarem as alterações sensoriais, físicas, químicas e microbiológicas em robalo (Dicentrarchus labrax) embalado em atmosfera modificada e em ar, encontraram altos níveis de desenvolvimento bacteriano nos primeiros dias de estocagem em aerobiose, alcançando valores acima de Log 6 UFC/g no $5^{\circ}$ dia de estocagem em ar e no 8으 embalagem em atmosfera modificada (EAM).

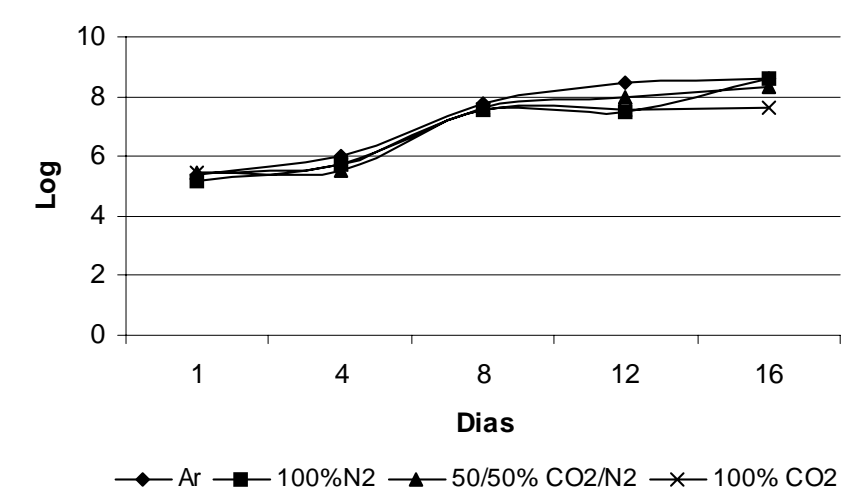

Figura 1: Valores médios em logaritmos das contagens de bactérias heterotróficas aeróbias mesófilas, em amostras de Pargo (Pagrus pagrus), embaladas em aerobiose e em diferentes atmosferas modificadas $(100 \%$ $\mathrm{N}_{2}, 50 / 50 \mathrm{CO}_{2} / \mathrm{N}_{2}$, e $\left.100 \% \mathrm{CO}_{2}\right)$, e armazenadas sob refrigeração $\left(2 \pm 2^{\circ} \mathrm{C}\right)$ durante 16 dias

As demais atmosferas obtiveram resultados semelhantes, oscilando pouco entre elas. Entretanto, a amostra embalada em $100 \% \mathrm{CO}_{2}$ demonstrou uma maior eficiência em retardar o crescimento bacteriano, pois ao final do experimento esta obteve valor abaixo de Log 8 UFC/g, enquanto todas as demais apresentaram valores superiores. Tais resultados foram similares aos obtidos por Ordóñez et al. (2000), que compararam o efeito da embalagem em atmosfera modificada e o ar na conservação de amostras de merluza (Merluccius merluccius), e concluíram que o ar obteve desempenho inferior se comparado às atmosferas enriquecidas com dióxido de carbono $\left(\mathrm{CO}_{2}\right)$.

De maneira geral, as amostras embaladas em atmosferas enriquecidas com $\mathrm{CO}_{2}$ demonstraram melhor desempenho por apresentarem valores de crescimento bacteriano muito abaixo dos obtidos pelas amostras embaladas em aerobiose, promovendo uma ampliação do prazo de vida comercial da espécie de pescado estudada. Concordando com Özogul et al. (2004) que analisaram o efeito da embalagem em atmosfera modificada sobre a conservação de sardinhas mantidas sob refrigeração e concluíram que, sob o ponto de vista microbiológico, as embalagens enriquecidas com $\mathrm{CO}_{2}$ comprovaram ser um melhor método de conservação.

Em relação ao pH, observa-se que na Figura 2 o valor inicial está de acordo com a faixa de $\mathrm{pH}$ post mortem de 5,4 a 7,2, citada por alguns autores, corroborando com os resultados obtidos por López-Gálvez et al. (1995) e Souza (2004), que obtiveram valores de $\mathrm{pH}$ iniciais de 5,8 e 5,6, respectivamente. Estes altos valores iniciais de $\mathrm{pH}$ podem ser explicados em função da baixa reserva de glicogênio muscular do pescado, e conseqüente pouca produção post mortem de ácido lático, que desta maneira contribui para a manutenção de um elevado $\mathrm{pH}$ final.

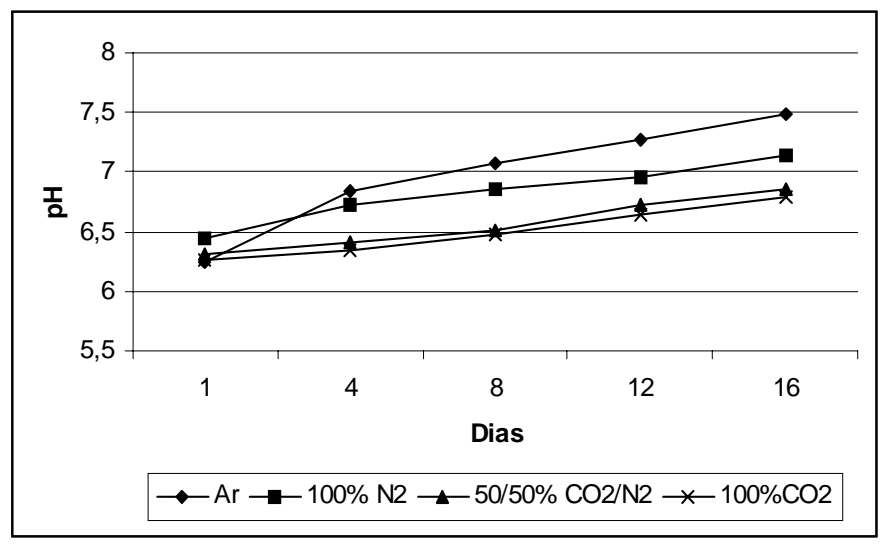

Figura 2: Valores médios de $\mathrm{pH}$, em amostras de Pargo (Pagrus pagrus), embaladas em aerobiose e em diferentes atmosferas modificadas $(100 \%$ $\mathrm{N}_{2}, 50 / 50$ CO2/N2, e $100 \%$ CO2), e armazenadas sob refrigeração $\left(2 \pm 2^{\circ} \mathrm{C}\right)$ durante 16 dias

Em todas as atmosferas obtiveram-se valores semelhantes de $\mathrm{pH}$ até o $8^{\circ}$ dia de estocagem. Deste momento em diante, 0 $\mathrm{pH}$ das amostras embaladas em aerobiose apresentou um progressivo aumento, até alcançar o valor de 7,49 no 16일 de estocagem. Este aumento é ocasionado pela degradação do pescado, onde a atividade enzimática e a ação das bactérias modificam a concentração de íons de hidrogênio livre através da decomposição de aminoácidos e da uréia (Ogawa e Maia, 1999), conforme observado por Dalgaard et al. (1993) que, ao estudarem a deterioração e a vida útil de bacalhau (Gadus morhua) embalados em vácuo e em atmosfera modificada, verificaram um maior incremento de $\mathrm{pH}$ nas amostras estocadas em atmosfera com baixa concentração de $\mathrm{CO}_{2}$. Dados similares aos obtidos por Ordóñez et al. (2000) que observaram um incremento de 0,7 unidades de $\mathrm{pH}$ para a atmosfera contendo $20 \%$ de $\mathrm{CO}_{2}$ e 0,4 para que continha $40 \%$ de $\mathrm{CO}_{2}$. No entanto, discordam dos resultados obtidos por Lalitha et al. (2005) que, ao estudarem as alterações microbiológicas e bioquímicas em Etroplus suratensis Bloch embalados em EAM, determinaram que não houve variação de $\mathrm{pH}$ entre as amostras em EAM e em aerobiose.

A pouca oscilação e estabilização do pH observadas por Lalitha et al. (2005) pode ser explicada pela difusão do $\mathrm{CO}_{2}$ no tecido do pescado, gerando a formação de ácido carbốnico que, apesar da produção de bases voláteis, funciona como uma barreira contra o aumento do pH (Devebere e Boskou, 1996).

$\mathrm{Na}$ análise sensorial, inicialmente a carne de pargo apresentou uma coloração branca, translúcida, com aspecto firme e elástico, e odor característico da espécie. Após quatro dias de estocagem, as amostras embaladas em aerobiose começaram a apresentar graves sinais de deterioração, como odor a ranço, coloração amarelada e consistência ligeiramente flácida, enquanto as amostras embaladas nas demais atmosferas apresentavam pouco ou nenhum sinal de deterioração. Passados oito dias de estocagem, as amostras embaladas em aerobiose e em $100 \% \quad \mathrm{~N}_{2}$ 
apresentaram fortes indícios de deterioração, como odor a ranço, coloração amarronzada, aspecto flácido e pegajoso. As atmosferas enriquecidas com $\mathrm{CO}_{2}$ proporcionaram os melhores resultados, posto que, após 12 dias de armazenagem, as amostras apresentaram um estado aceitável para o consumo.

$\mathrm{O}$ efeito das duas atmosferas enriquecidas com $\mathrm{CO}_{2}$ nas características sensoriais foi semelhante, no entanto as amostras armazenadas em $100 \% \mathrm{CO}_{2}$ apresentaram aparente flacidez após 12 dias de estocagem. Essa flacidez pode ser explicada pela alta concentração de $\mathrm{CO}_{2}$ que pode ocasionar uma diminuição da capacidade de retenção de água das proteínas miofibrilares, provocando um gotejamento intenso e uma perda de turgidez das fibras. Formação de

\section{Referências}

ALBANESE, D.; CINQUANTA, L.; LANORTE, M.T.; DI MATTEO, M. Squid (Sepia officinalis) stored in active packaging: some chemical and microbiological changes. Italian Journal of Food Science, v. 17, n. 3, p. 325-332, 2005.

BRASIL. Ministério da Agricultura, Pecuária e Abastecimento. Secretaria nacional de Defesa Agropecuária. Laboratório Nacional de Referência Animal (LANARA). Métodos analíticos oficiais para controle de produtos de origem animal e seus ingredientes. I Métodos Microbiológicos. Brasília, DF, 1981a, 42 p.

BRASIL. Ministério da Agricultura, Pecuária e Abastecimento. Secretaria Nacional de Defesa Agropecuária. Laboratório Nacional de Referência Animal (LANARA). Métodos analíticos oficiais para controle de produtos de origem animal e seus ingredientes. II Métodos Físico Químicos. Brasília, DF, 1981b, 123 p.

CONTE-JÚNIOR, C. A.; FERNÁNDEZ, M. e MANO, S.B. Use of carbon dioxide to control the microbial spoilage of bullfrog (Rana catesbeiana) meat. In: Mendez-Vilas, A. Modern Multidisciplinary Applied Microbiology: Exploiting Microbes and Their Interactions. Hardcover: Ed. Wiley-VCH, 2006, $822 \mathrm{p}$.

DALGAARD, P.; GRAM, L.; HUSS, H. H. Spoilage and shelf life of cod fillets packed in vacuum or modified atmosphere. International Journal of Food Microbiology, v. 19, n. 4, p. 283-294, 1993.

DEVEBERE, J;BOSKOU, G. Effect of modified atmosphere packaging on the TVB/TMA- producing mricroflora of cod fillets. Internacional Journal of Food Microbiology, v. 31, n. 1-3, p. 221-229, 1996.

IBAMA. Estatística da pesca 2002 - Brasil grandes regiões e unidades da federação. Tamandaré, 2004. 129p. Disponível em: <https//: www.ibama.gov.br>. Acesso em 23 dez. 2005.

LALITHA, K.V.; SONAJI, E.R.; MANJU, S.; JOSE, L.; GOPAL, T.K.S.; RAVISANKAR, C.N. Microbiological and biochemical changes in pearl spot (Etroplus suratensis Bloch) stored under modified atmospheres. Journal of Applied Microbiology, v. 99, p. 1222-1228, 2005.

LOPES, M.M.; MÁRSICO, E.T.; SOBREIRO, L.G.; SILVA, L.P.; CONTEJÚNIOR, C.A.; PARDI, H.S.; MANO, S.B. Efeito da embalagem em atmosfera modificada sobre a conservação de sardinhas (Sardinella odor ácido, alteração de textura e perda de líquido (drip), que também foram descritos por Stammen et al. (1990). Albanese et al. (2005), estudando as alterações químicas e microbiológicas apresentadas por Sepia officinalis em EAM, verificaram o aparecimento do drip a partir do 5o dia de estocagem, contabilizando uma perda final de $2,5 \%$ do peso total do pescado.

\section{Conclusões}

De acordo com os resultados é possível concluir que a embalagem contendo $100 \% \mathrm{CO}_{2}$ se destacou das demais, mostrando bom desempenho na preservação da carne de pargo, aumentando sua vida útil e sendo eficiente na manutenção dos parâmetros de qualidade.

brasiliensis). Revista Portuguesa de Ciências Veterinárias, v. 99, p. 207-210, 2004.

LÓPEZ GÁLVEZ, D.; HOZ, L.; ORDÓNEZ, J. A. Effects of carbon dioxide and oxygen enriched atmospheres on microbiological and chemical in refrigerated tuna (Thunnus alalunga) steaks. Journal of Agriculture and Food Chemistry, v. 43, p. 483-490, 1995.

MANO, S. B.; ORDÓÑEZ, J. A. e FERNANDO G. G. Aumento de la vida útil y microbiología de la carne de pavo envasada en atmósferas modificadas. Revista Brasileira de Ciência Veterinária, v. 6, n. 2, p.55-65, 1999.

OGAWA, M.; MAIA, E.L. Manual de Pesca-Ciência e Tecnologia de Pescados. v.1. São Paulo: Livraria Varela, 1999.

ORDÓÑEZ, J. A. et al. Microbial and physicochemical modifications of hake (Merluccius merluccius) stakes stored under carbon dioxide enriched atmosphere. Journal of the Science of Food and Agriculture, v. 80, p. 1831-1840, 2000.

ÖZOGUL, F.; POLAT, A.; ÖZOGUL, Y. The effects of modified atmosphere packaging and vacuum packaging on chemical, sensory and microbiological changes of sardines (Sardina pilchardus). Food Chemistry, v. 85, p. 49-57, 2004.

POLI, B.M.; MESSINI, A.; PARISI, G.; SCAPPINI, F.; VIGIANI, V.; GIORGI, G.; VICENZINI, M. Sensory, physical, chemical and microbiological changes in European sea bass (Dicentrartchus labrax) fillets packed under modified atmosphere/air or prepared from whole fish stored in ice. International Journal of Food Science and Technology, v. 41, p. 444-454, 2006.

SORHEIM, O.; NISSEN, H. Current technology for modified atmosphere packaging of meat. Disponível em: http: //www.foodsciencecentral. com /library.html\#ifis/3800. Acesso em 20 de janeiro de 2005.

SOUZA, W.G. Efeito da embalagem em atmosfera modificada sobre a conservação de lombo de atum (Thunnus albacares). 2004. $76 \mathrm{f}$. Dissertação (Mestrado em Medicina Veterinária) - Programa de PósGraduação em Higiene Veterinária e Processamento Tecnológico de Produtos de Origem Animal - Universidade Federal Fluminense, 2004. STAMMEN, K.; GERDES, D.; CAPORASO, F. Modified atmosphere packaging of seafood. Critical Reviews in Food Science and Nutrition, v. 29, n. 5, p.301-331, 1990. 